Mestre em Comunicação, consultor e professor de Marketing na Faculdade de Negócios da Moda da Universidade Anhembi Morumbi.

\title{
As perspectivas do fast-fashion no Brasil
}

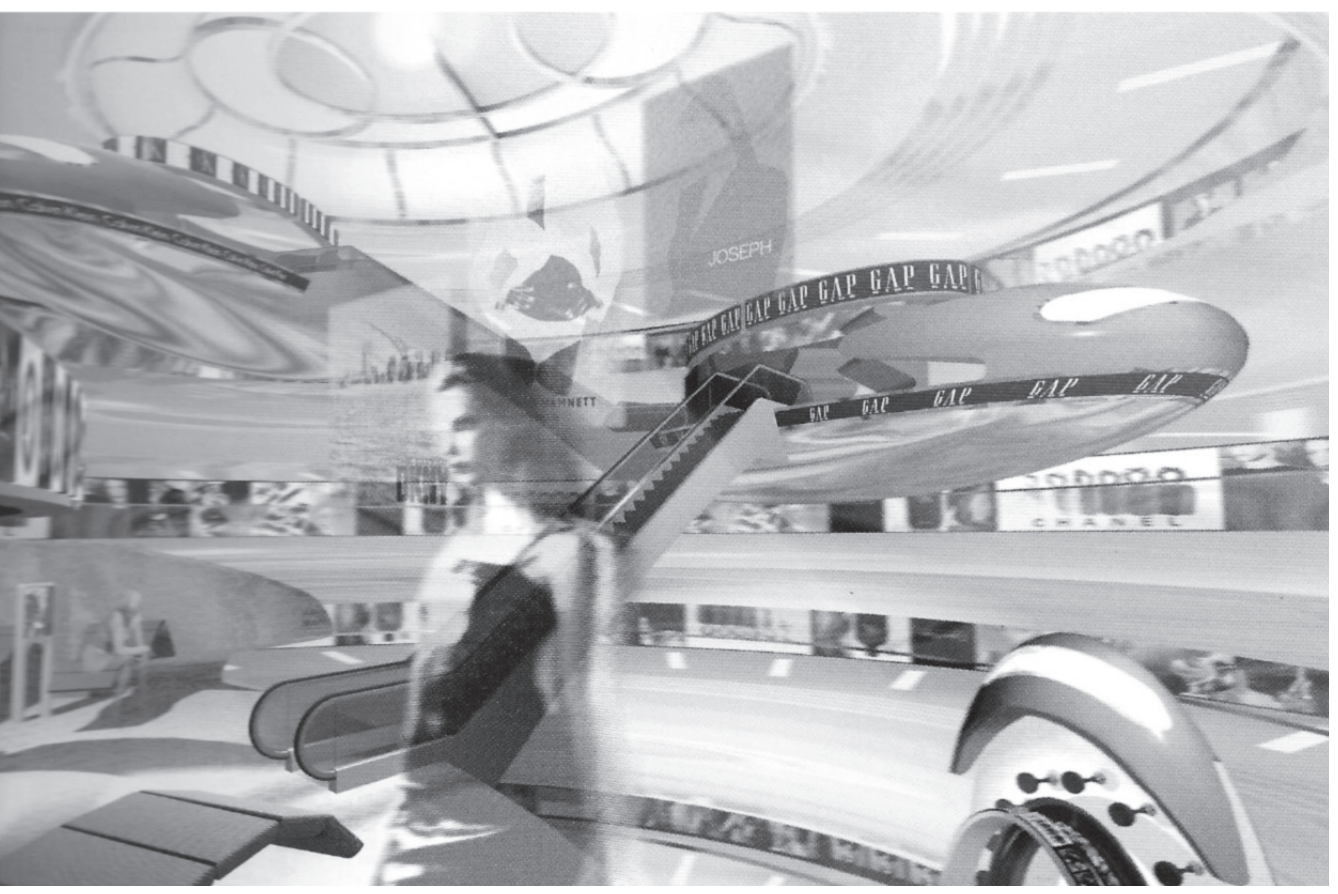

Ainda que o termo fast-fashion já seja conhecido pelos que vivem da moda, ou em torno dela, é importante fazermos algumas considerações para abordar suas perspectivas a partir da importância que o mercado brasileiro atribui à sua prática.

0 modelo de negócios do varejo da rede espanhola Zara é a base para a aplicação no Brasil do que pensamos ser o fast-fashion, ainda que sem muito conhecimento dos processos necessários para nos apropriarmos corretamente da expressão.

Até bem pouco tempo, operar com o fast-fashion no Brasil representava apenas reposição rápida do novo e levemente diferente produto na vitrina do varejo, por meio de maior frequência de compras nas confecções ou no atacado. Mas por que o varejo precisa de reposição rápida de estoque, de produtos diferentes, comprando mais frequentemente?

Dois fatores podem ser apontados pela descoberta do fast-fashion "à brasileira". 0 primeiro deles, coerente com nossas raízes antropofágicas, é que acolhemos os modelos estrangeiros e os adaptamos ao jeito brasileiro - condições econômicas, comportamento, cultura, samba, futebol, voracidade de consumo, sincretismo religioso, entre outros aspectos. Assim, o fast-fashion brasileiro foi uma resposta intuitiva ao poderio chinês de produtos baratos. Baratos mas iguais. Para se viabilizar uma encomenda a preço baixo, a qualquer fornecedor chinês, há a necessidade de um grande volume de produção do mesmo item. Não há diferenciação, razão pela qual é possível se produzir a preços baixíssimos, afora impostos. Portanto, o varejo que tem produto chinês em sua loja correrá grande risco de ver seus concorrentes oferecendo o mesmo produto. Entretanto, por se tratar de artigos de preços reduzidos, a margem de lucratividade só pode vir do giro dos produtos; se houver itens semelhantes nas lojas, ou de fim de estação, a guerra de preços e prejuízos será inevitável. A saída para ter produtos diversificados importados da China é aumentar o volume de compra, o que só é possível por um grande atacadista. 
Uma sondagem especial da Confederação Nacional da Indústria $(\mathrm{CNI})^{1}$ revela que $48,4 \%$ das indústrias brasileiras "querem investir mais em qualidade e design", como contra-ataque à presença da China e revela que a percepção do empresariado nacional em relação aos produtos chineses é de baixa qualidade e carência de design.

Assim, a saída encontrada foi importar o modelo de negócios que pensamos ser o fast-fashion e 0 adaptarmos à nossa realidade competitiva.

0 segundo aspecto refere-se à explosão de consumo de moda dos brasileiros - ambos os sexos e todas as idades. Nos últimos anos, o crescimento da renda possibilitou 0 aumento do poder de consumo dos brasileiros. Não que os consumidores, principalmente das classes $C$ e $D$, não tivessem acesso aos produtos de moda - as redes C\&A, Marisa, Renner, Riachuelo comprovam isso. Todavia, o crescimento do mercado de trabalho, aliado ao crédito fácil e à pressão da mídia, resultou em um aumento significativo de consumo e de demandas do consumidor por maior diversidade de produtos. Isso fez com que o varejista procurasse sempre ter novidade. A solução encontrada pelos varejistas foi adquirir menor quantidade de produtos a cada compra e, em contrapartida, aumentar o número de compras, que deveriam contemplar sempre um mix diferente. Por conseguinte, cresceu também a busca por novos fornecedores, principalmente na confecção por atacado, que passou a operar com o fast-fashion para fidelizar os clientes varejistas.

$\mathrm{Se}$, por um lado, a pressão por constantes novidades igualmente atingiu o mercado varejista, por outro, fez diminuir o estoque do varejo. Produto que fica na vitrina por mais de uma semana é considerado "fora de moda" e possivelmente é descartado com facilidade.

Essa mudança de comportamento do varejo é fundamental para se entender no Brasil o fenômeno fast-fashion - a função de estocar passa do varejista ao atacado pronta-entrega.

A explosão de consumo também foi beneficiada pela ansiedade e euforia do mercado consumidor de moda por novidades e diferenciação. 0 cenário político-econômico favoreceu esse comportamento. Automóveis e produtos eletrodomésticos tiveram corte de impostos, buscando-se manter o nível de emprego, e um dos resultados foi a euforia geral para o aumento de consumo, uma vez que o Brasil foi um dos poucos países atingidos pela crise econômica que afetou os mercados europeu, americano e japonês, desde 2008, a enfrentar a crise com certa tranquilidade. As ações do governo federal, visando também às eleições presidenciais, foram diretamente responsáveis por esse clima superotimista.

Esses dois fatores com seus efeitos colaterais podem ser considerados como fundamentais para a explosão de consumo de moda no Brasil.

Contudo, as perspectivas para o fast-fashion dependem mais da qualidade da reação das empresas do que do comportamento do mercado. 0 impacto da mudança de mercado - para mais ou para menos - obrigará cada empresa a buscar uma solução particular e inovadora que talvez não se aplique ao mercado ou aos seus concorrentes. Essa solução única dentro das características do fast-fashion requer parâmetros mais definidos - a euforia que tomou conta de 2010 não deu vez ao planejamento, e agora o empresário precisa planejar para mudar ou poderá ser surpreendido.

0 economista, professor e consultor italiano Enrico Cietta, em seu livro A revolução do fast-fashion ${ }^{2}$ e em artigo intitulado Fast-Fashion uma oportunidade para as empresas brasileiras? ${ }^{3}$, lança uma luz nesse cenário relatando experiências bem-sucedidas do modelo italiano, bem como insucessos de outros modelos.

0 modelo tradicional de desenvolvimento de coleções sempre partiu da concepção de estilistas, bureaux de moda, chegando ao mercado após certo prazo, muito longo em termos de investimentos e muito curto para cumprir os cronogramas de lançamentos.

Esse é o primeiro impacto no mercado nos últimos tempos. 0 sentido da onda inverteu-se. Cada vez mais esses centros de pesquisas e estilistas orientam-se para captar o comportamento do mercado e rapidamente dar respostas em termos de produtos de moda. As confecções brasileiras adaptam-se para esse novo processo de desenvolvimento de produto.

Entretanto, não se trata apenas de desenvolver um produto, é necessário mudar a mentalidade e repensar os meios de captar os sinais do mercado; é fundamental rever toda a cadeia têxtil. 0 valor que cada empresa agregará estará atrelado ao modelo utilizado na aplicação do fast-fashion. 
Qual a grande diferença entre o sucesso do modelo italiano e o dos outros que não deram resultados tão favoráveis?

0 modelo italiano prevê que os produtos fast-fashion tenham estilo e qualidade, sejam inovadores e estejam imbuídos de valor cultural. Tudo isso com rapidez entre concepção e comercialização. Junto com a rapidez exige-se qualidade, valor e design.

0 que aconteceu na Europa, segundo Cietta, pode extrapolar para o Brasil - comportamento imprevisivel do consumidor, diferenças gritantes entre as regiões, novas formas de comercialização, de maneira que o centro das atenções não é mais o produto e, por conseguinte, a indústria, mas o ponto de venda - atacado, varejo, e-commerce e, até mesmo, o mercado informal (pequeno comércio, ambulantes e "sacoleiras").

As tecelagens, confecções, malharias e os fabricantes de acessórios criam as principais tendências de moda e procuram não perder de vista as demandas de seus consumidores, promovendo as alterações que se façam necessárias para agradar a seus clientes.

0 que o modelo de negócios chamado fast-fashion oferece é a redução do risco a toda cadeia distributiva, e essa é a grande diferença positiva do modelo italiano sobre todas as outras tentativas de acelerar o fluxo de mercadorias, porque, vale ressaltar, 0 mercado varejista é ágil; é o varejo quem muda suas preferências e tendências.

Grandes marcas mundiais, como Zara e H\&M, captam dos mercados nos diversos países onde atuam o comportamento das pessoas que são seu público-alvo e debruçam-se sobre as variáveis de comportamento que influenciam as demandas de seu público.

A partir dessas tendências, será importante que fornecedores e clientes tenham mais proximidade entre eles, para oferecer o valor que o mercado exige: qualidade, design, rapidez, preço, como também o posicionamento da marca a longo prazo. Importante destacar que o valor intrínseco à marca corre sérios riscos quando se alteram o estilista, o gerente de vendas, o quadro de vendedores, representantes ou mesmo os fornecedores.

Em vez de recorrer à troca de pessoal como solução para atingir novas formas de desempenho, a empresa precisa conhecer primeiro seus pontos fortes e fracos e deve procurar se consolidar naquilo que o mercado entende como positivo. Nesse sentido, o empresário deve acentuar os contatos com seu círculo de relacionamento de negócios e, ainda, contratar profissionais consultores para apoiá-lo num diagnóstico fundamental - a avaliação de seus colaboradores e concorrentes que são a base para a tomada de decisão.

As premissas do fast-fashion (valor, qualidade, design, preço, rapidez) só podem ser atendidas na cooperação entre fornecedores e clientes de toda a cadeia têxtil. Cada nicho de mercado tem suas preferências e barreiras, e somente no ambiente cooperativo é que o sucesso será alcançado.

0 consumidor busca atendimento na loja que, por sua vez, busca atendimento em seus fornecedores que, por sua vez, buscam atendimento nas tecelagens, malharias e nos fabricantes dos acessórios (calçados, bolsas, joias etc.). Consequentemente, as soluções são individuais e dizem respeito a cada empresa - a integração dos processos produtivos e comerciais é condição imprescindivel ao sucesso do fast-fashion no Brasil.

\section{NOTAS}

${ }^{[1]}$ O Estado de S. Paulo, São Paulo, 4 fev. 2011. Economia, p. B3.

${ }^{[2]}$ CIETTA, Enrico. A revolução do fast-fashion. São Paulo: Estação das Letras e Cores, 2010.

${ }^{[3]}$ dObra[s], Estação das Letras e Cores, São Paulo, v. 4, n. 10, out. 2010, p. 18-21.
} 